\title{
ROLE OF MICRO RNA-21 IN EGYPTIAN PATIENTS WITH ISCHEMIC HEART DISEASE
}

\author{
By Tarek Abd El-Kareim El-Dahshan, Ahmad Fathey Abd El-Aziz and Ahmed Kamal Harfoush* \\ Mohammed Abd El-Fattah Mokhtar Khalaf, Hassan Abd El-Aziz Gaber, \\ Departments of Clinical Pathology and Cardiology*, Faculty of Medicine- Al-Azhar \\ University \\ Corresponding Author: Mohammed Abdel-Fattah Mokhtar Khalaf, \\ E-mail:mak_3turbo@yahoo.com
}

\begin{abstract}
Background: Ischemic heart diseases are major sources of morbidity and mortality worldwide. Several biomarkers have been suggested to aid in the diagnosis of myocardial infarction and unstable angina. Multiple micro-RNAs, a class of regulatory ribonucleic acids, have been studied in ischemic heart disease patients for a potential role in diagnosis.

Objective: To study the role of micro RNA-21(miRNA21 or miR21) in Egyptian patients with ischemic heart diseases(IHD), myocardial infarction (MI) and unstable angina (UA) to evaluate its diagnostic value in IHDs.

Patients and Methods: This prospective case-control study included 50 subjects, divided into two groups: Patient group including 30 subjects, and control group including 20 subjects. Subjects were subjected to full history taking and clinical assessment, routine lab investigations, cardiac markers assay, and determination of serum expression of Micro RNA-21 using real-time polymerase chain reaction (PCR). This study was conducted on patients attending at cardiology department, Al-Hussein University Hospital. Study started in March 2018, and ended in October 2018.
\end{abstract}

Results: Micro-RNA expression profile showed that miR-21 was up-regulated in MI and UA patients in general, with a statistically extremely highly significant difference $(\mathrm{p}=<0.001)$. Its diagnostic performance was marvelous, but couldn't distinguish between UA and MI.

Conclusions: In conclusion, we found that Micro RNA-21 showed a statistically extremely high significant up regulation in MI and UA patients, with strong diagnostic performance, but couldn't distinguish between UA and MI. Micro RNA-21 might be biomarker for ischemic heart disease.

Keywords: Micro-RNA, Cardiac, Fold-changes, Biomarker.

\section{INTRODUCTION}

IHD is defined as acute or chronic form of cardiac disability due to imbalance between supply and demand of oxygenated blood. In more than 90\% cases the cause of myocardial ischemia is reduced blood flow due to coronary atherosclerosis. Thus IHD is often termed coronary artery disease (CAD) or coronary heart disease (CHD) (Porwal et al., 2016).

Ischemic heart disease is the leading cause of morbidity and mortality worldwide. Early diagnosis and intervention is integral in reducing injury in acute myocardial infarction (AMI). 
Moreover, raised cardiac troponins (cTn) are not entirely AMI specific, and they can be chronically raised in patients with congestive cardiac failure or chronic kidney disease. The establishment of novel biomarkers for AMI has, therefore, become an important focus of medical research (Robinson et al., 2018).

Compared to cTn, the biochemical golden standard for diagnosis of ACS, Micro RNAs (miRNAs) are detectable in the circulation at an earlier time point after MI. cTn is part of the myofibrillar apparatus, being large protein complexes, whereas the majority of miRNAs are also protein bound, but relatively smaller and are released in a controlled way, which can explain the time difference in release after MI. miRNAs can be released more quickly, which benefits early MI diagnosis and revascularization therapy (Deddens et al., 2013).

miRNAs are a class of tiny, regulatory, non-coding RNAs, about 22 nucleotides in length. These molecules are critical posttranscriptional regulators of gene expression (Yates et al., 2013). miRNAs have been implicated in the regulation of many cellular and developmental processes. They play a crucial role in healthy individuals and their dysregulation have also been implicated in a wide range of diseases, including diabetes, cardiovascular disease, kidney disease, and cancer. The expression level of multiple miRNAs differs in different diseases, and thus analysis of expression profiles of multiple miRNAs used for diagnostics, as well as to predict drug response (Paul et al., 2017).

The present study aimed to study the role of microRNA21 in Egyptian patients with IHD, MI and UA to evaluate its diagnostic value in IHDs.

\section{PATIENTS AND METHODS}

This study was conducted on patients attending at cardiology department, AlHussein University Hospital. Study protocol was approved by the Research and Ethical Committee of Faculty of Medicine at Al-Azhar University. Informed consent was obtained from patient / patient's legal guardians before enrollment. Study started in March 2018, and ended in October 2018.

The study included 50 adult persons of both sexes. Subjects were divided into 2 groups. The first one was the patients group that included thirty adult patients with newly diagnosed MI or UA. The second group was the control group that included twenty normal subjects. Study subjects were subjected to the following: full history taking, routine lab investigations (liver enzymes, kidney functions, blood sugar profiles and HbAlc and Lipid profile), and clinical data acquisition. Patients were also subjected to cardiac biomarker assays including CK Total, CK-MB and Troponin I.

Both groups were also subjected to determination of serum expression of Micro RNA-21. Micro-RNA was extracted from serum using "miRNeasy Mini kit" (Qiagen, Germany). Reverse transcription was done using "miScript II RT Kit” (Qiagen, Germany). Amplification was done using target specific TaqMan ${ }^{\circledR}$ Small RNA Assay and Universal PCR Master Mix II. All steps were done according to manufacturer recommendations. Threshold cycle (CT) values were registered for each sample 
well, and were normalized against the house keeping gene RNU-43. Fold changes of miRNA21 expression were calculated using $2^{\wedge}-\mathrm{CT}$ method, where (Tawfik et al., 2019):

Fold Change $=2^{\wedge-\Delta \Delta C T}$

$\Delta \Delta \mathrm{C}_{\mathrm{T}}=\Delta \mathrm{CT}_{\text {patients }}-\Delta \mathrm{CT}_{\text {control }}$

$\Delta \mathrm{C}_{\mathrm{T}}$ (relative expression) $=\mathrm{CT}$ miRNA of interest $-\mathrm{CT}$ housekeeping RNA

\section{Statistical analysis:}

Analysis of the collected data was performed using IBM $^{\odot}$ SPSS $^{\odot}$ Statistics version 23 (IBM $^{\odot}$ Corp, Armonk, NY, USA). Qualitative data were introduced as number and percentages whereas quantitative data were presented as mean and standard deviations. The comparative studies between 2 quantitative data groups were examined by Mann Witney U test. Diagnostic accuracy of continuous variables was examined using Receiver operator characteristic curve (ROC) analysis. $\mathrm{P}$-value $\leq 0.05$ was considered significant.

\section{RESULTS}

Out of 30 patients, $15(50 \%)$ had MI, and $15(50 \%)$ had UA. Demographic, laboratory and clinical data of studied population. The majority of patients enrolled in current study were hypertensive $(73.4 \%)$ and smokers $(60 \%)$ and half of them were diabetic (Table 1).

Table (1): Demographic, laboratory and prognostic scores data of studied population

\begin{tabular}{|c|c|c|c|}
\hline \begin{tabular}{|ll} 
Parameters & Groups \\
\end{tabular} & Patients $(n=30)$ & Control $(n=20)$ & p value \\
\hline \multicolumn{4}{|l|}{ Demographic Data } \\
\hline Age(years) (mean \pm SD) & $54 \pm 8.6$ & $51.2 \pm 7$ & 0.14 \\
\hline Gender & $\begin{array}{l}8 \text { females }(26.6 \%) \\
22 \text { males }(73.4 \%)\end{array}$ & $\begin{array}{l}6 \text { females }(30 \%) \\
14 \text { males }(70 \%)\end{array}$ & 0.79 \\
\hline \multicolumn{4}{|l|}{ Clinical Diagnosis (n, \%) } \\
\hline UA & $15(50 \%)$ & & \\
\hline MI & $15(50 \%)$ & & \\
\hline \multicolumn{4}{|c|}{ Clinical Data on admission $(n, \%)$} \\
\hline Diabetic & $15(50 \%)$ & & \\
\hline Hypertensive & $22(73.3 \%)$ & & \\
\hline Smoker & $18(60 \%)$ & & \\
\hline \multicolumn{4}{|l|}{ Basic Lab (mean \pm SD) } \\
\hline $\begin{array}{l}\text { Cholesterol, Total } \\
(\mathrm{mg} / \mathrm{dl})\end{array}$ & $201.16 \pm 49.7$ & $171.2 \pm 19.1$ & 0.016 \\
\hline Triglyecrides $(\mathrm{mg} / \mathrm{dl})$ & $227.15 \pm 67.5$ & $169.45 \pm 20.7$ & 0.001 \\
\hline LDL-c $(\mathrm{mg} / \mathrm{dl})$ & $113.21 \pm 45.4$ & $91.86 \pm 37.5$ & 0.06 \\
\hline HDL-c (mg/dl) & $42.63 \pm 8.3$ & $45.45 \pm 10.3$ & 0.04 \\
\hline HbA1c (\%) & $6.64 \pm 1.3$ & $5.1 \pm 0.45$ & 0.051 \\
\hline
\end{tabular}


Table (2): Cardiac markers data of different studied groups Cardiac markers data of control vs. AMI patients. Cardiac markers data of control vs. UA patients.

\begin{tabular}{|c|c|c|c|}
\hline $\begin{array}{ll}\text { Cardiac Markers } & \text { Groups } \\
\end{array}$ & Patients $(n=30)$ & $\begin{array}{l}\text { Control } \\
(\mathbf{n}=20)\end{array}$ & $\mathbf{P}$ \\
\hline $\begin{array}{l}\text { CK }(\mathbf{I U} / \mathbf{L}) \\
\text { Mean } \pm \text { SD }\end{array}$ & $350.1 \pm 174$ & $28 \pm 15$ & 0.03 \\
\hline $\begin{array}{l}\text { Troponin I (ng/ml) } \\
\text { Mean } \pm \text { SD }\end{array}$ & $2.75 \pm 2.2$ & $0.19 \pm 0.11$ & 0.04 \\
\hline $\begin{array}{l}\text { CK-MB (ng/ml) } \\
\text { Mean } \pm \text { SD }\end{array}$ & $58.84 \pm 32.5$ & $3.7 \pm 1.4$ & 0.049 \\
\hline $\begin{array}{ll}\text { Cardiac Markers } & \text { Groups } \\
\end{array}$ & $\begin{array}{c}\text { AMI Patients } \\
(n=15)\end{array}$ & $\begin{array}{c}\begin{array}{c}\text { Control } \\
(n=20)\end{array} \\
\end{array}$ & $\mathbf{P}$ \\
\hline $\begin{array}{l}\text { CK }(\mathbf{I U} / \mathbf{L}) \\
\text { Mean } \pm \text { SD }\end{array}$ & $552.4 \pm 76.8$ & $28 \pm 15$ & 0.012 \\
\hline $\begin{array}{l}\text { Troponin I (ng/ml) } \\
\text { Mean } \pm \text { SD }\end{array}$ & $5.4 \pm 2.5$ & $0.19 \pm 0.11$ & 0.002 \\
\hline $\begin{array}{l}\text { CK-MB (ng/ml) } \\
\text { Mean } \pm \text { SD }\end{array}$ & $112.2 \pm 91.9$ & $3.7 \pm 1.4$ & 0.005 \\
\hline $\begin{array}{ll}\text { Cardiac Markers } & \text { Groups } \\
\end{array}$ & $\begin{array}{c}\text { UA Patients } \\
(n=15)\end{array}$ & $\begin{array}{c}\text { Control } \\
(\mathbf{n}=20)\end{array}$ & $\mathbf{P}$ \\
\hline $\begin{array}{l}\text { CK }(\mathbf{I U} / \mathbf{L}) \\
\text { Mean } \pm \text { SD }\end{array}$ & $174.8 \pm 16.6$ & $28 \pm 15$ & 0.04 \\
\hline $\begin{array}{l}\text { Troponin I (ng/ml) } \\
\text { Mean } \pm \text { SD }\end{array}$ & $0.1 \pm 0.0$ & $0.19 \pm 0.11$ & 0.55 \\
\hline $\begin{array}{l}\text { CK-MB (ng/ml) } \\
\text { Mean } \pm \text { SD }\end{array}$ & $5.5 \pm 5.0$ & $3.7 \pm 1.4$ & 0.72 \\
\hline
\end{tabular}

There was a statistically significant difference in all cardiac enzymes parameters in patients vs. control group. CK-MB and troponin I were statistically highly significant. No significant differences were found in cardiac markers data of control vs. UA patients except CK which is statistically significant (Table 2).

The miRNA-21 expression profiles showed that miRNA-21 was up-regulated in patients compared to control group. Fold changes showed extremely high statistical significance. Concerning the correlation of miRNA-21 and diagnosis, miRNA-21 showed the highest upregulation in MI patients. However, no significant difference between the two groups was found (Table 3).

Table (3): miRNA-21 expression in patients vs. control and subgroups according to clinical diagnosis (Mean \pm SD)

\begin{tabular}{|c|c|c|c|}
\hline miRNA & Patient & Control & p value \\
\hline miRNA-21 & $131.68 \pm 66.67$ & $1.1795 \pm 0.86$ & $<0.001$ \\
\hline & Angina Patients & AMI & \\
\hline miRNA-21 & $20.74 \pm 21.28$ & $242.62 \pm 499.46$ & 0.181 \\
\hline
\end{tabular}

\# Cut-off value for change in expression is 1 . Values $>1$ indicate up-regulation, while values $<1$ indicate down-regulation. 
The diagnostic power of studied miRNA-21 was investigated using ROC curves for fold change values of patients and healthy control subjects (Figure 1).
The performance of miRNA-21 was powerful and statistically significant. However, it couldn't discriminate between UA and MI (Figure 2).

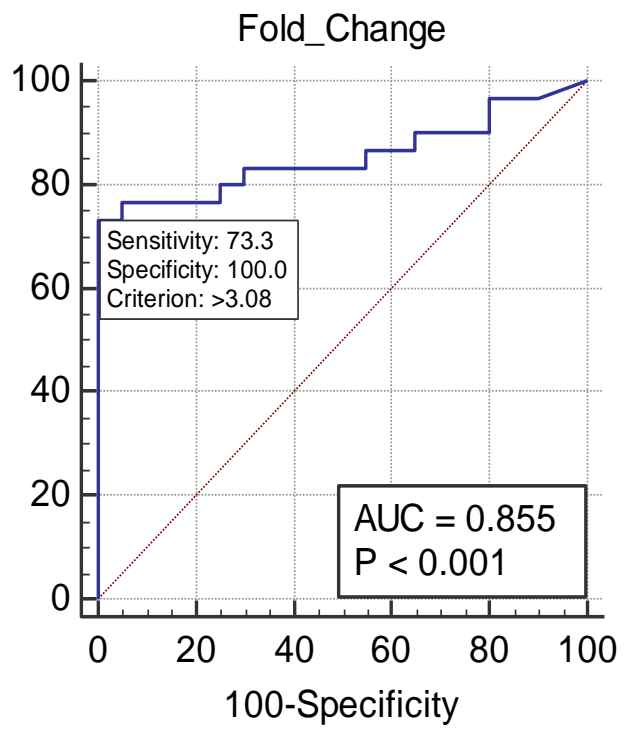

Figure (1): Receiver operating characteristic (ROC) curve for diagnostic performance of studied miRNA-21 in patients vs. control

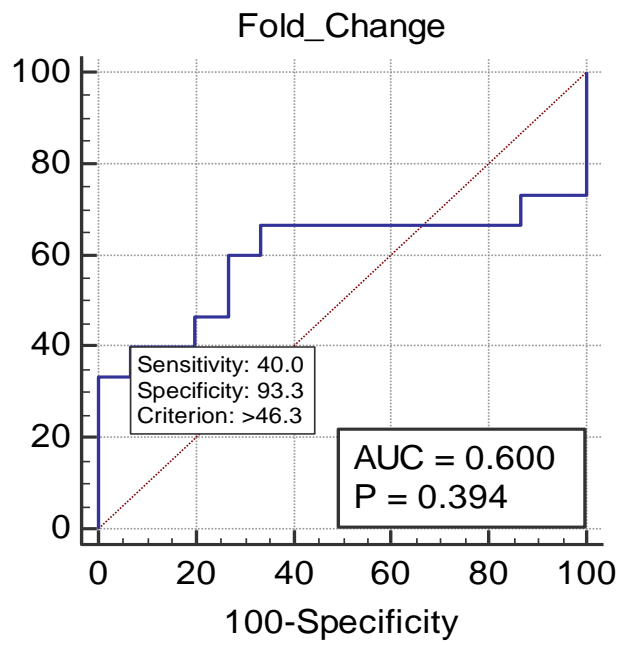

Figure (2): $\quad$ ROC curve for diagnostic performance of studied patient subgroups

The diagnostic performance characteristics of miRNA-21 following ROC curve analysis of fold change values to distinguish AMI patients from control.
Showed $\mathrm{P}$ value was significant and its diagnostic performance was strong (Figure 3). 


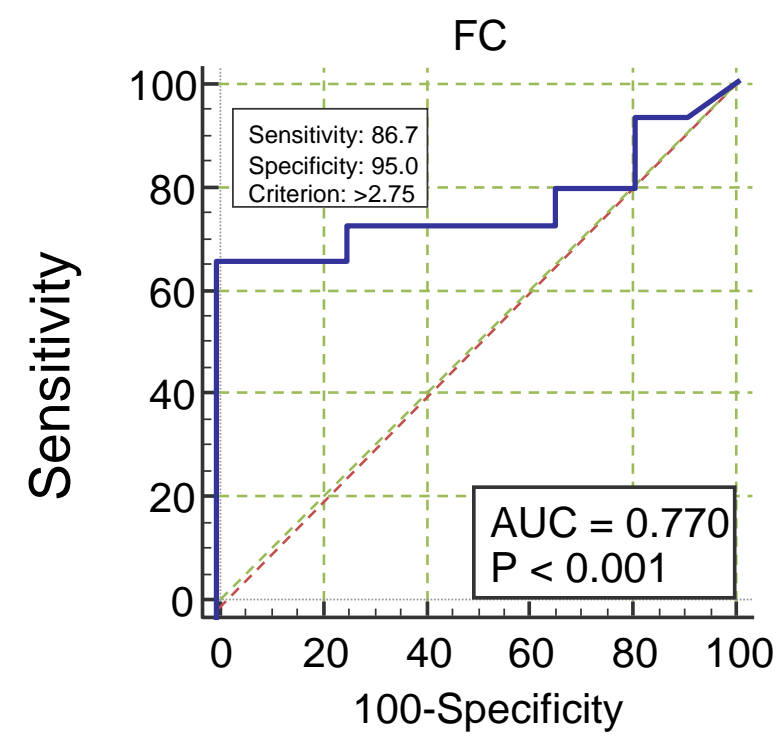

Figure (3): ROC Curve of miRNA-21 in study AMI patients vs. control

The diagnostic performance characteristics of miRNA-21 following ROC curve analysis of fold change values to distinguish UA patients from control.
Showed $\mathrm{P}$ value was significant and its diagnostic performance was strong (Figure 4).

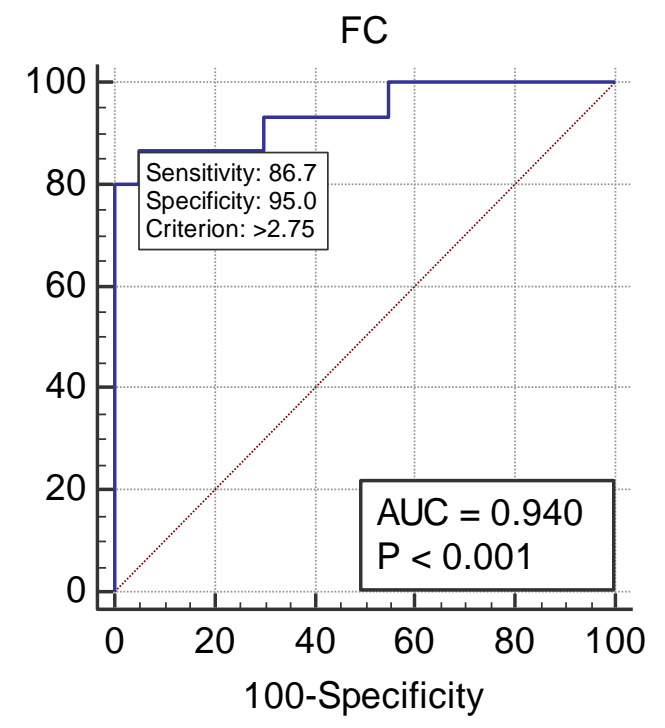

Figure (4): ROC Curve of miRNA-21 in study UA patients vs. control

\section{DISCUSSION}

In this study, the expression of miRNA-21 was up-regulated in patients compared to control group this up- regulation was statistically significant. This result considered better than cardiac markers. 
Olivieri et al. (2013) also found that miRNA-21 was elevated 12 fold in ACS patients vs. controls. miRNA-21 was also elevated in NSTEMI vs. control vs. CHF as reported by Long et al. (2012). Circulating miRNA-21 was elevated 18.9fold after AMI as reported by Oerlemans et al. (2012). Desjardins and Conklin (2010) also showed that the miRNA-21 level was significantly higher in the ACS group (10.52 fold).

Mythili and Malathi (2015) found that miRNA-21 in the serum of elderly patients (>65 years) with AMI was greater than in elderly patients with unstable angina and healthy elderly people, but their reported difference was significant, most probably due to larger sample size. Also they showed that the level of expression of serum miRNA-21 in elderly patients with AMI was positively correlated with serum CK-MB and cTnI. CK-MB is one of the isoforms of CK, derived from the myocardium and is an important clinical diagnostic indicator in patients with AMI. The findings of this study supported the possibility that increased expression of miRNA-21 in the serum of elderly patients with AMI may be related to the apoptosis of myocardial cells, and could be a potential diagnostic marker for AMI.

In our study, and in agreement with Mythili and Malathi (2015) study, miRNA-21 expression in AMI patients was greater than UA patients and control group. We also agree with the previous study in positive correlation between the expression of miRNA-21 and CK-MB and Troponin.

Circulating miRNA-21 was elevated 18.9-fold after MI and also detectable in the hs-cTnT-negative subgroup as well. Moreover, miRNA-21 was elevated even within $3 \mathrm{~h}$ after the onset of symptoms (Oerlemans et al., 2012). At day 2 postMI, the levels of miRNA-21 decreased but surprisingly increased again at day 5 . At day 90, the concentration had returned to baselines (Zile et al., 2011).

The individual ROC of miRNA-21 had an AUC of 0.76 and was thereby lower than cTn or hs-cTnT. However, combined with miRNA-499 and -1, miRNA-21 added diagnostic value (AUC 0.89) compared to hs-cTnT (0.86) (Oerlemans et al., 2012). Therefore, miRNA-21does have an advantage at early time points after MI when cTn is not detectable yet (Deddens et al., 2013).

The individual ROC of miRNA-21 in our study had an AUC of 0.855, much higher than the value of 0.76 reported by Oerlemans et al. (2012).

Serum miRNA-21 level in $2-\Delta \mathrm{Ct}$ value was significantly higher in ACS patients than the stable CAD patients. The serum levels of miRNA-21and hs-CRP (an inflammation marker) were significantly higher in the ACS group than the stable CAD group. The serum miR-21 had significant positive correlations with hs-CRP, and age. The serum miR-21 had a significant negative correlation with HDL-C, but no correlations with other traditional risk factors for cardiovascular disease such as total cholesterol, triglycerides, and LDL-C (Darabi et al., 2017). We agreed with the previous study. In contrast to the previous study, we found that HDL-C is significant and had a positive correlation with miRNA-21 but the previous study shows negative 
correlation with miRNA-21 in ACS patients.

Found that miRNA-21 initially fell 2 days post-AMI, increased 5 days postAMI, and returned to baseline levels at later post-AMI time points. These results indicated that serially profiling miRNAs in the plasma of post-AMI patients may have both mechanistic and prognostic significance (Zile et al., 2011).

Expression pattern studies of myocardial tissue reveal that several miRNAs are up- or downregulated upon MI (Bonauer et al., 2010 and Fiedler et al., 2011). Upregulation of miRNA-21, 214 , and -233 and down regulation of miRNA- $29 b$ and -149 in the border zone of human infracted myocardium were shown (Van Rooij et al., 2010).

Only miRNA-34a, miRNA-21 and miRNA-23a were significantly differentially expressed in the plasma of CAD patients. miRNA-34a, miRNA-21 and miRNA-23a elevated in CAD patients, which mean that these miRNAs might serve as biomarkers of CAD development and progression (Han et al., 2015).

Quantitative real-time PCR was used for analyses of serum miRNA-21 expressions in all patients with ACS and stable CAD. Analyses by $\Delta \mathrm{ct}$ method (Desjardins and Conklin, 2010) showed that the miRNA- 21 level in $2-\Delta \mathrm{Ct}$ value was significantly higher in the ACS group compared with the stable CAD group.

It has been shown that miRNA-1, miRNA-21 or miRNA-499 in combination with hs-cTnT achieved significant higher diagnostic performance than hs-cTnT alone. Furthermore, these particular
miRNAs were already significantly elevated in ACS-diagnosed patients with a symptom commencement of below $3 \mathrm{~h}$ or with an initially negative hs-cTnT (Samani and Meder, 2016).

The levels of miRNA-21 remained higher after adjustment for the risk factors (age, hypertension, hyperlipidemia, and diabetes). Moreover, the combination of these miRNAs and $\mathrm{m}$-HS can increase the specificity and sensitivity for detecting patients with UA. The heart score has been used to estimate the risk of patients with chest pain in the ED (Backus et al., 2013).

In a study by Ling et al. (2020), they found that the expression of serum exosomal miRNA-126, miRNA-21, and phosphatase and tensin homologue (PTEN) differed between UA and AMI patients from those of healthy controls, although the direction of differences varied; miRNA-126 and PTEN levels were increased in the patients, whereas miRNA-21 levels were lower in the patients than in the controls. There was no significant difference in the expression levels of miRNA-21 between the UA and AMI groups, whereas PTEN and miRNA126 levels were higher in the AMI patients than in the UA patients. Furthermore, they found that miRNA-21 may be a candidate diagnostic biomarker for ACS, which could effectively distinguish ACS patients from healthy people at the early stage of disease onset.

In our study, we found that miRNA-21 levels are higher in patients than controls which was in contrast with the previous study. Our study agreed with the previous study that there is no difference expression in UA and AMI groups. Also 
our study agreed with previous study in considering miRNA-21as diagnostic biomarker for ACS.

Regarding the expression of miRNA21 and neutrophil lymphocyte ratio in acute myocardial infarction patients group and control group, the expression of miRNA-21 and neutrophil lymphocyte ratio in the acute myocardial infarction patients group was significantly higher than that in the control group. ROC curves were plotted to analyze the diagnostic value of miRNA-21 and neutrophil lymphocyte ratio in AMI between the observation group and the control group. The area under the curve (AUC) of miRNA-21 was 0.909 (95\% CI: 0.877 $0.941)$, indicating that miR-21 can be used as a biomarker of AMI (Gao et al., 2019).

Our study agreed with Gao et al. (2020) study, both showed miRNA-21 expression was up regulated in patient group than control group. Both consider miRNA-21 as biomarker for AMI.

In a study of Zhang et al. (2016), they supported the potential clinical value of circulating miRNA-21 as novel a biomarker for AMI. They showed that plasma miRNA-21 level was greatly elevated in patients with AMI; and more importantly, high correlations between certain indicators of myocardium injury and this microRNA were found. ROC analysis further highlighted its diagnostic functions in AMI. Taken together, this study demonstrates that circulating miRNA-21 might be a useful biomarker for the diagnosis of AMI, and reinforces the emerging concept that integrates the application of circulating microRNAs in disease diagnosis and prognosis.
The present study, which reported that the elevation of plasma levels of miRNA21 in AMI patients, is in agreement with the Northern blot and in situ hybridization data obtained from heart biopsy of MI patients in the previous study of Van Rooij et al. (2010). They found that miRNA-21 was also differentially presented in the blood of patients with different extent of coronary artery stenosis; and this study identified that miRNA-21 exhibited similar diagnostic accuracy with traditional markers including $\mathrm{CK}$, CKMB and cTnI. Given the aforementioned disadvantages of the traditional biochemical markers, this study put forward that miRNA-21 can be used independently or at least complementarily to evaluate the severity of myocardium injury. These findings, therefore, supported the perspective proposed by a study of (Kukreja et al., 2011).

Our study agreed with Zhang et al. (2016) who considered miRNA-21 as biomarker for AMI, while Xu et al. (2015) and others disagreed with our study in considering miRNA-21 as a biomarker for AMI.

\section{Study Limitation:}

During this study, small number of subjects included in this study made generalization of results unrealistic. Cost of reagents was an additional limitation to inclusion of more subjects. It is advisable to conduct more studies including more subjects to overcome the obstacles of small sample sizes and allow better sampling of general population. Expansion of investigation to include more miRNAs in the same study is recommended to achieve better disease profiling. 


\section{CONCLUSION}

miRNA-21 showed a statistically significant up regulation in MI and UA patients, with good diagnostic performance and weak discriminative power between the two disease categories.

\section{REFERENCES}

1. Backus BE, Six AJ and Kelder JC. (2013): Prospective validations of the HEART score for chest pain patients at the emergency department.Int J Cardiol., 168: 2153-8.

2. Bonauer A, Carmona G, Iwasaki M, Mione $M$ and Koyanagi M. (2010): MicroRNA-92a controls angiogenesis and functional recovery of ischemic tissues in mice. Science, 324: 1710-1713.

3. Darabi F, Aghaei M and Movahedian A. (2017): Association of serum microRNA-21 levels with Visfatin, inflammation, and acute coronary syndromes. Heart Vessels, 32:549-557.

4. Deddens JC, Colijn JM and Oerlemans MIFJ. (2013): Circulating MicroRNAs as Novel Biomarkers for the Early Diagnosis of Acute Coronary Syndrome. $\mathrm{J}$ of Cardiovasc Trans Res., 6: 884-898.

5. Desjardins $P$ and Conklin $D$ (2010): NanoDrop microvolume quantitation of nucleic acids. J Vis Exp., (45):2565-67.

6. Fiedler J, Jazbutyte $\mathrm{V}$ and Kirchmaier BC. (2011): MicroRNA-24 regulatesvascularity after myocardial infarction. Circulation, 124:720-730.

7. Gao C, Zhao D and Wang J. (2019): Clinical significance and correlation of microRNA-21 expression and the neutrophil-lymphocyte ratio in patients with acute myocardial infarction. Clinics, 74:e1237.

8. Han H, Qu G, Han C, Sun T, Li F, Wang $J$ and Luo $S$ (2015): MiR-34a,
miR-21 and miR-23a as potential biomarkers for coronary artery disease: a pilot microarray study and confirmation in a 32 patient cohort. Experimental \& Molecular Medicine, 47: 138-142.

9. Kukreja RC, Yin C and Salloum FN. (2011): MicroRNAs: new players in cardiac injury and protection. Mol Pharmacol., 80: 558-564.

10.Ling H, Guo Z, Shi Y, Zhang $L$ and Song C. (2020): Serum Exosomal MicroRNA-21, MicroRNA-126, and PTEN Are Novel Biomarkers for Diagnosis of Acute Coronary Syndrome. Front Physiol., 11:654-57.

11.Livak $K$ and Schmittgen $T$ (2001): Analysis of relative gene expression data using real time quantitative PCR and the 2^-CT method. Methods, 25: 402-8.

12.Long G, Wang $F$ and Duan $Q$ (2012): Human circulating microRNA-1 and microRNA-126 as potential novel indicators for acute myocardial infarction. Int J Biol Sci., 8:811-818.

13.Mythili $S$ and Malathi N. (2015): Diagnostic markers of acute myocardial infarction. J Nucl Cardiol., 3: 1-6.

\section{Oerlemans MI, Mosterd A and Dekker} MS. (2012): Early assessment of acute coronary syndromes in the emergency department: the potential diagnostic value of circulating microRNAs. EMBO Mol Med., 4:1176-85.

15.Olivieri F, Antonicelli R, Lorenzi M, Lisa R, La Sala $L$ and Galeazzi $R$. (2013): Diagnostic potential of circulating miR-499-5p in elderly patients with acute non ST-elevation myocardial infarction. Int J Cardiol., 31:531-536.

16.Paul P, Chakraborty A and Sarkar D. (2017): Interplay between miRNAs and Human Diseases: A Review. Journal of Cellular Physiology, 233(3):2007-2018. 
17.Porwal V, Khandelwal S, Jain $D$ and Gupta S. (2016): Histological Classification of Atherosclerosis and Correlation with Ischemic Heart Disease. A Autopsy Based Study Annals of Pathology and Laboratory Medicine, 3(2):103-104.

18. Robinson S, Follo $M$ and Haenel $D$. (2018): Droplet digital PCR as a novel detection method for quantifying microRNAs in acute myocardial infarction. Int J Cardiol., 257: 247-254.

19.Samani OS and Meder B (2016): microRNA assays for acute coronary syndromes. De Gruyter J., 3(4): 183-188.

20.Tawfik NA, El-Dydamoni OA, Abozaid SY, Ebrahem EE and Abd EL Rahim MMMA. (2019): Serum miRNA-146a and miRNA-155 as Novel Biomarkers in Lupus Nephritis Activity with Systemic Lupus Erythematosus. American Journal of Biochemistry, 9: 21-34.

21.Van Rooij E, Sutherland LB and Thatcher JE. (2010): Dysregulation of
microRNAs after myocardial infarction reveals a role of miR-29 in cardiac fibrosis. Proc Natl Acad Sci USA., 105: 1302713032.

22.Xu F, Xu L, Wang $M$ and Feng G. (2015): The accuracy of circulating microRNA-21 in the diagnosis of colorectal cancer: a systematic review and meta-analysis. Colorectal Dis., 17: 100107.

23.Yates LA, Norbury CJ, and Gilbert RJ. (2013): The long and short of microRNA. Cell, 153(3): 516-9.

24.Zhang Y, Liu YJ, Liu T and Yang J. (2016): Plasma microRNA-21 is a potential diagnostic biomarker of acute myocardial infarction. Eur Rev Med Pharmacol Sci., 20(2):323-9.

25.Zile MR, Mehurg SM and Arroyo JE. (2011): Relationship between the temporal profile of plasma microRNA and left ventricular remodeling in patients after myocardial infarction. Circulation Cardiovascular Genetics, 4: 614-619. 
دور الحمض الريبوزى النووي المصغر رقم 21 في

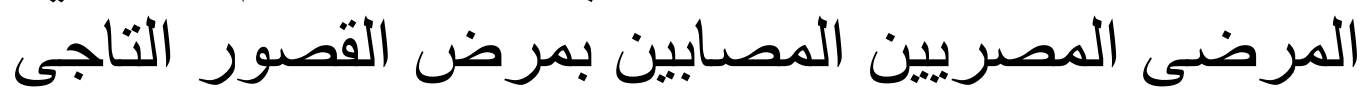
محمد عبدالفتاح مختار خلف, حسن عبدالعزيز جابر, طارق عبدالكريم الدهثان, أحمد

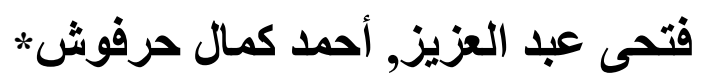

قسمي الباثولوجيا الاكلينيكية والكيميانية, وأمراض القلب والأوعية الامويةث، كلية الطب، جامعة الأزهر

E-mail: mak_3turbo@yahoo.com

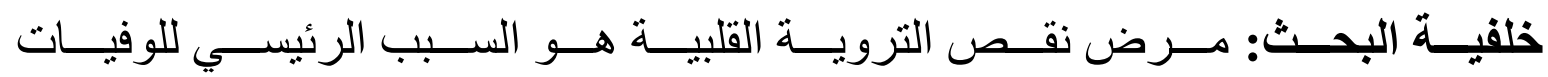

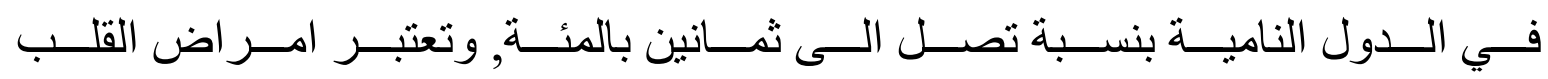

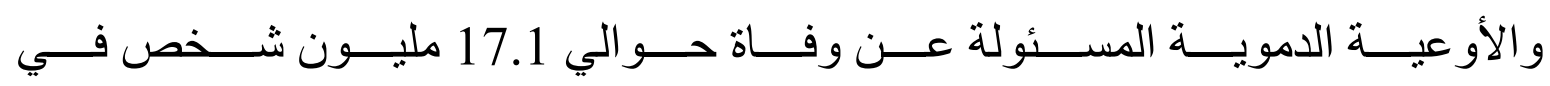

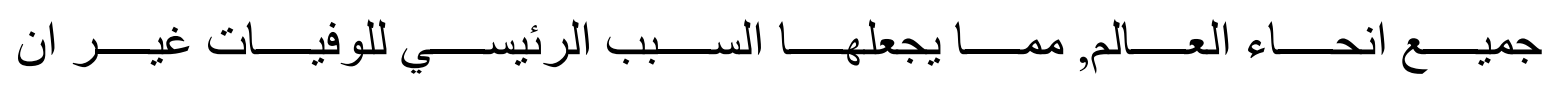

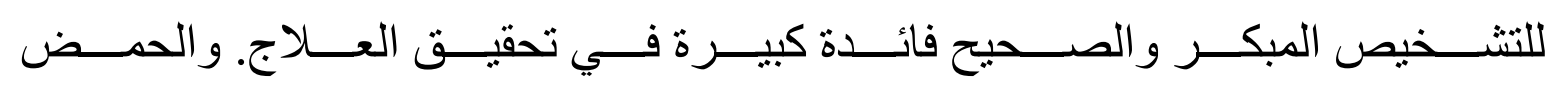

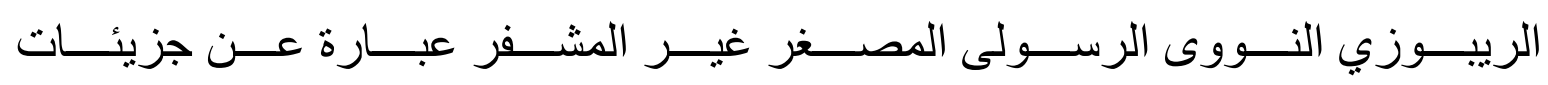

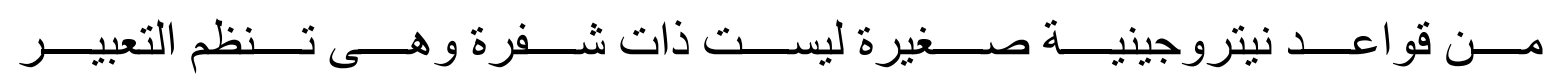

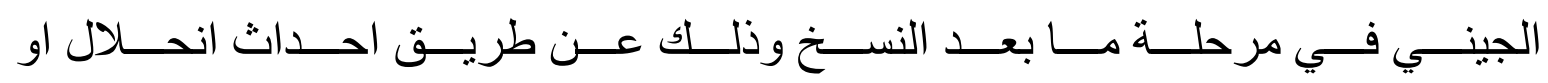

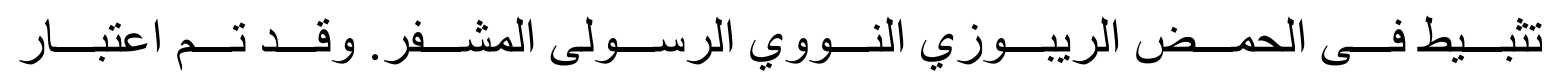

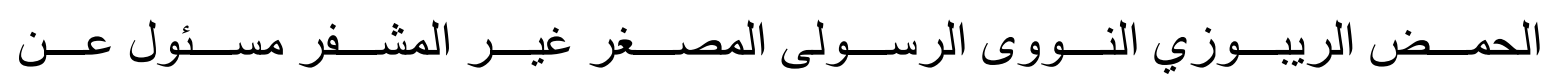
تنظيم 90\% من الجينات البشرية.

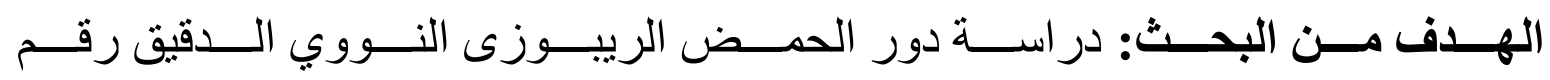
21 في المرضى المصريين المصابين بمرض القصور التاجى.

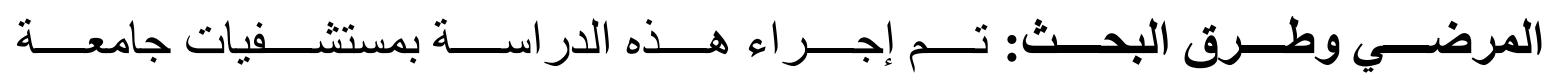

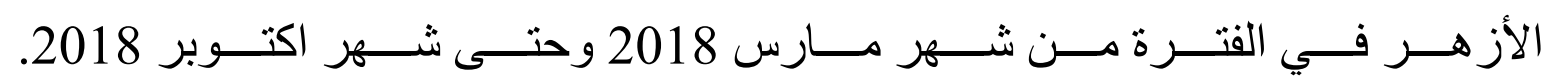

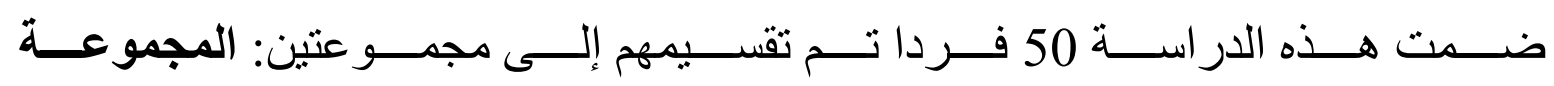

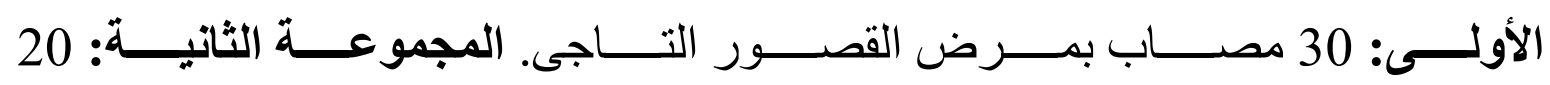


مــن الأشــخاص الأصــــاء كمجموعــة ضـــابطة متســقة مـــع المجمو عــة الأولـى من حيث السن و الجنس.

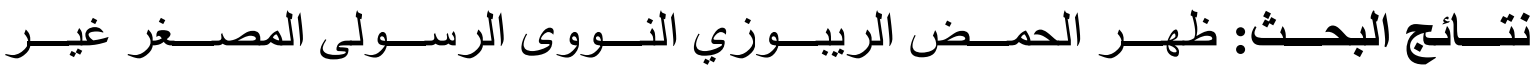
المشــفر 21 جليــا فـي المرضـــى المصـــابين بقصــور الثــريان التــاجي مقارنـــة

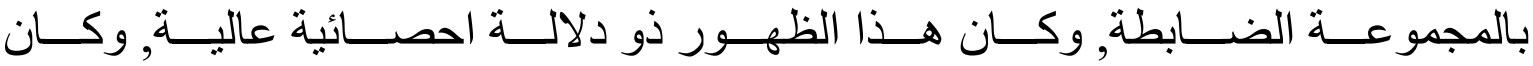

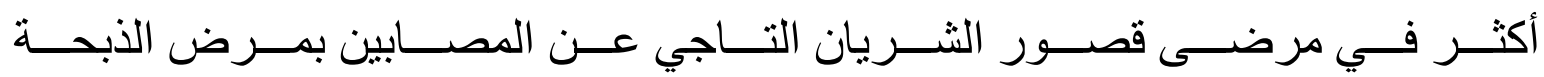
الصدرية ولكن بصورة غير مؤثرة.

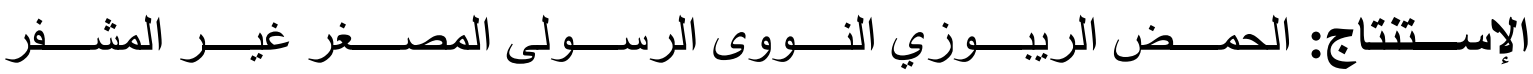

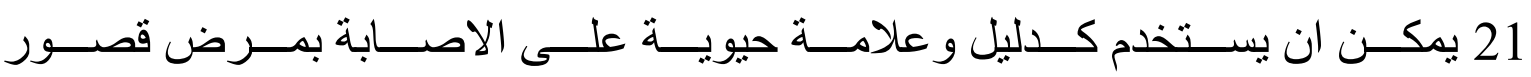

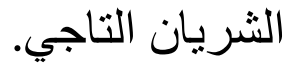

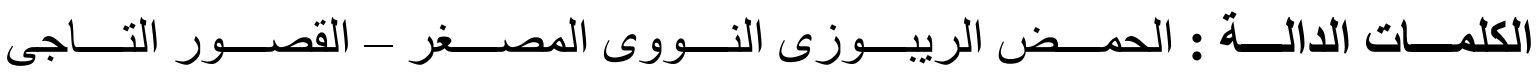

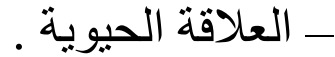

